\title{
Benzoxime carbaldehyde prevents rheumatoid arthritis in a rat model by inhibition of oxidative damage
}

\author{
Zhi-ming Li, Yanming Wang, Shujun Gai, Tao He* \\ Department of Orthopaedic Surgery, Dezhou People's Hospital, Dezhou, Shandong, 253014, China \\ *For correspondence: Email: TrulaVsch@yahoo.com; Tel/Fax: +86-534-2265514
}

Sent for review: 18 December 2017

Revised accepted: 21 July 2018

\begin{abstract}
Purpose: To investigate the effect of benzoxime carbaldehyde $(B X C D)$ on rheumatoid arthritis $(R A)$ in a rat model.

Methods: Thirty male Sprague-Dawley rats were assigned randomly to 5 groups (6 rats per group): normal control, RA, and three treatment groups. Rats in the normal control and RA groups received normal saline, whereas those in the three treatment groups were given 2, 5 or $10 \mathrm{mg} / \mathrm{kg}$ of $B X C D$ daily for 30 days by intraperitoneal injection. Pressure pain was analysed using electronic pressure pain detector, while the expressions of interleukin (IL)-6, interleukin (IL)-1 $\beta$, nuclear factor (NF)-KB $p 65$ and tumor necrosis factor (TNF)- $\alpha$ in serum were determined using enzyme-linked immunosorbent assay (ELISA) kits.

Results: Treatment of RA rats with $B X C D$ for 30 days led to significant $(p<0.05)$ recovery in pain threshold. At a dose of $10 \mathrm{mg} / \mathrm{kg}, B X C D$ decreased pain threshold value to a level comparable to that in normal control rats, and decreased arthritis score to 1, relative to arthritis score of 16 in untreated animals. Malondialdehyde (MDA) level was 4-fold higher in untreated RA rats than in normal and $B X C D$-treated groups. BXCD treatment increased the activities of superoxide dismutase (SOD), catalase (CAT) and glutathione peroxidase (GSH-PX), and blocked increases in the blood levels of IL-6, $I L-1 \beta, N F-K B$ p65 unit, and TNF- $\alpha$. Western blot assay showed that $B X C D$ treatment prevented increase in the level of cyclooxygenase-2 (COX-2) in RA rat tissues.

Conclusion: These results indicate that $B X C D$ prevents $R A$ in a rat model via inhibition of expressions of inflammatory cytokines and decrease in oxidative stress. Thus, BXCD has a strong potential for the management of RA.
\end{abstract}

Keywords: Rheumatoid arthritis, Pain threshold, Antioxidant enzymes, Inflammation, Inflammatory cytokines

\begin{abstract}
This is an Open Access article that uses a funding model which does not charge readers or their institutions for access and distributed under the terms of the Creative Commons Attribution License (http://creativecommons.org/licenses/by/4.0) and the Budapest Open Access Initiative (http://www.budapestopenaccessinitiative.org/read), which permit unrestricted use, distribution, and reproduction in any medium, provided the original work is properly credited.

Tropical Journal of Pharmaceutical Research is indexed by Science Citation Index (SciSearch), Scopus, International Pharmaceutical Abstract, Chemical Abstracts, Embase, Index Copernicus, EBSCO, African Index Medicus, JournalSeek, Journal Citation Reports/Science Edition, Directory of Open Access Journals (DOAJ), African Journal Online, Bioline International, Open-J-Gate and Pharmacy Abstracts
\end{abstract}

\section{INTRODUCTION}

Rheumatoid arthritis (RA) is a joint disorder characterized by infiltration of inflammatory cells, hypertrophy and degeneration of cartilage and bone [1]. The mechanism underlying the aetiology of RA is yet to be fully understood [1]. The main focus of treatment in patients suffering from joint disease is aimed at avoiding permanent disability associated with RA [2]. The initial stage of RA involves erosion of bone and cartilage tissues at the joints [2]. Thus, the arrest 
of the growth and proliferation of synovial tissues is considered to be of significance in the treatment of RA [3]. Due to associated inflammatory disorder, RA is linked to increased expressions of inflammatory cytokines [4]. Indeed, IL-1 $\beta$ and TNF- $\alpha$ are elevated in the tissues of RA patients [4]. In addition, COX-2 is expressed very markedly in the joints of RA patients $[5,6]$. It is also believed that antigencatalysed, challenge-chained immune reaction plays an important role in the development and progression of RA [7, 8]. Moreover, genetic and environmental factors induce Th1 cells to produce higher content of IL-1, IL-6 and TNF- $\alpha$ $[7,8]$. The expressions of these cytokines facilitate $B$ cell activation and ultimately lead to the formation of synovial lesions $[7,8]$.

Thus, studies aimed at understanding the aetiology of RA, and developing efficient methods for its treatment are crucial. In the present study, the role of BXCD (Figure 1) in RA treatment in a rat model, and its mechanism of action were investigated.<smiles>O=CC1C=Nc2ccccc2O1</smiles>

Figure 1: Chemical structure of benzoxime carbaldehyde

\section{EXPERIMENTAL}

\section{Animals}

Male Sprague-Dawley rats (weighing about 270 g) were used in this study. They were purchased from the Experimental Animal Centre of China Medical University (Shenyang, China). The animals were housed individually in cages under $12 / 12 \mathrm{~h}$ light and dark cycle at constant temperature of $23{ }^{\circ} \mathrm{C}$. The housing atmosphere was humidity-controlled, and the rats were provided access to feed and water ad libitum. The study was approved by the Committee for Animal Care and Use of Sun Yat-Sen University, China (no. SYSU-206), and the experimental protocols were performed according to the guidelines of Care and Use of Laboratory Animals by the National Institute of Health, China [9].

\section{Preparation of RA rat model}

The RA rat model was prepared according to previous protocol [10]. The rats were kept in cages under $12 / 12 \mathrm{~h}$ light and dark cycle in an animal house with a humidity of $~ 85 \%$ and temperature $5-7{ }^{\circ} \mathrm{C}$ for 20 days. They were anesthetized with isoflurane $\left(2 \%\right.$ in $\left.\mathrm{O}_{2}\right)$ on day 21. Freund's complete adjuvant $(10 \mathrm{mg} / \mathrm{mL}$; Sigma-Aldrich, St. Louis, MO, USA) was injected subcutaneously into the right foot of each rat between $2^{\text {nd }}$ and $3^{\text {rd }}$ toes. Examination of the animals $72 \mathrm{~h}$ later revealed inflammation in the right ankles, and the appearance red coloured swellings in the forelimbs and contralateral limbs. These symptoms clearly indicated the development of arthritis in the rats.

\section{Treatment strategy}

Thirty rats were randomly assigned into 5 groups of 6 animals each. The five groups were normal control, RA group, and three treatment groups. The rats in the three treatment groups were injected intraperitoneally with BXCD at doses of 2,5 or $10 \mathrm{mg} / \mathrm{kg}$ daily for 30 days. The rats in the normal control and RA groups received normal saline.

\section{Determination of pain threshold}

After 30 days of treatment, pressure pain was measured in rats in the five groups. Pressure pain was determined using an electronic pressure pain detector (Somedic AB, Hörby, Sweden) according to the manual protocol. The pressure pain for each animal was measured in triplicates, with an intervening period of $20 \mathrm{~min}$ in accordance with normal procedures [11].

\section{Determination of RA scores}

Rats in all the groups were examined for RA scores after 30 days of treatment. The RA scores were classified according to the degree of arthritis thus: arthritis in whole paw and digits was assigned scores of 11 - 15; arthritis in more than two joints was scored between 6 and 10, while arthritis in only two joints was scored between 1 and 5 . Absence of arthritis was scored 0 .

\section{Determination of oxidative stress parameters in rat serum}

At the end of treatments, blood samples were collected from each rat and centrifuged at 3,000 $\mathrm{g}$ at $4{ }^{\circ} \mathrm{C}$ for $20 \mathrm{~min}$. The serum samples were then analysed for SOD, MDA, CAT and GSH-Px using commercially available kits (Nanjing Jiancheng Co Ltd) [12].

\section{Assay of blood levels of cytokines}

The rats were anaesthetized using $1 \%$ mebumal sodium (Sigma-Aldrich). Blood sample was 
collected from the carotid artery of each rat and subjected to centrifugation for $20 \mathrm{~min}$ at $3,500 \mathrm{~g}$. The supernatant was stored at $-78{ }^{\circ} \mathrm{C}$ under liquid nitrogen prior to assay of IL-6, IL-1 $1 \beta$, NFKB p65 and TNF- $\alpha$ using enzyme-linked immunosorbent assay (ELISA) kits (Santa Cruz Biotechnology, Inc., Santa Cruz, CA, USA) in accordance with the manufacturer's protocol.

\section{Western blot assay for COX-2 expression}

The expression of COX-2 in rat tissues was determined with western blot assay. The rats were sacrificed under $1 \%$ pentobarbital anaesthesia, and $15 \mathrm{mg}$ tissue sections were excised. The tissue samples were then incubated for 45 min under ice-cold conditions with RIPA buffer (Rockland, Gilbertsville, PA, USA). The tissue homogenates obtained were subjected to centrifugation at $4{ }^{\circ} \mathrm{C}$ for $15 \mathrm{~min}$ at $10,000 \mathrm{~g}$. Protein concentration was determined with bicinchoninic protein assay kit (Pierce, Rockford, IL, USA). Resolution of the lysates $(5 \mu \mathrm{g})$ on 12.5 $\%$ SDS-PAGE gel was followed by transfer to polyvinylidene difluoride membrane (Bio-Rad, Hercules, CA, USA) using electroblotting. The membranes were incubated overnight at $4{ }^{\circ} \mathrm{C}$ with monoclonal primary antibodies against COX-2 (dilution 1: 1, 200; catalog no. sc376861), and $\beta$-actin (dilution 1:1, 200; catalog no. sc-7210). Both antibodies were purchased from Santa Cruz Biotechnology, Inc. (Dallas, TX, USA). After incubation, the membranes were washed three times using Tris-buffered saline with Tween-20. The membranes were then subjected to incubation with polyclonal goat anti-mouse antibody (catalog no. 7076; dilution 1: 2, 000; Cell Signalling Technology, Inc.) for $1 \mathrm{~h}$. Development of the blot was achieved using enhanced chemiluminescence kit (Intron Biotechnology Inc., Seongnam, Korea).

\section{Statistical analysis}

Data are presented as mean $\pm S D(n=3)$. Data analysis was performed with one-way analysis of variance (ANOVA) followed by the least significant difference (LSD), using SPSS 13.0 software (SPSS, Inc., Chicago, IL, USA). Differences were considered statistically significant at $p<0.05$.

\section{RESULTS}

\section{BXCD treatment improved pain threshold in RA rats}

Pain threshold was significantly decreased in the RA, when compared with rats in the normal control group ( $p<0.05$, Figure 2). However,
BXCD treatment for 30 days brought about significant recovery in pain threshold, with the 10 $\mathrm{mg} / \mathrm{kg}$ BXCD group resulting in pain threshold comparable to that of normal control animals (Figure 2). These findings suggest that BXCD mitigates RA in the rat model.

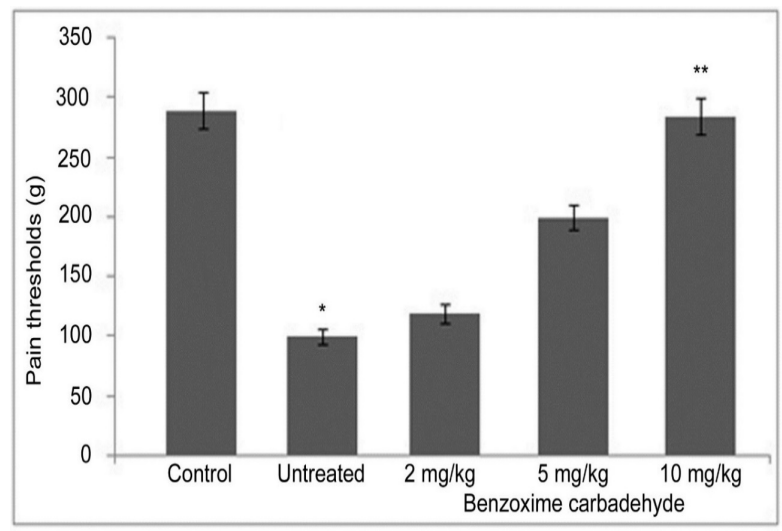

Figure 2: Effect of $B X C D$ on pain threshold in rats with RA. Following induction of RA, the rats were treated with 2,5 or $10 \mathrm{mg} / \mathrm{kg} \mathrm{BXCD}$ for 30 days. ${ }^{*} p<0.01$, compared with normal control rats; ${ }^{* *} p<0.05$, compared with untreated RA rats

\section{BXCD decreased RA scores in rats}

Arthritis score was significantly higher in RA rats than in the normal control group (Table 1). On the other hand, arthritis score in the RA rats after 30 days of BXCD treatment was very low. In the $10 \mathrm{mg} / \mathrm{kg}$ BXCD-treated group, the arthritis score was 1 , whereas untreated RA group had arthritis score of 16 (Table 1). These results are shown in Table 1.

Table 1: Effect of BXCD on arthritis score in rats with RA

\begin{tabular}{lc}
\hline Group & RA score \\
\hline Control & 0 \\
Untreated & 16 \\
$2 \mathrm{mg} / \mathrm{kg} \mathrm{BXCD}$ & 12 \\
$5 \mathrm{mg} / \mathrm{kg} \mathrm{BXCD}$ & 7 \\
$10 \mathrm{mg} / \mathrm{kg} \mathrm{BXCD}$ & 1 \\
\hline
\end{tabular}

\section{BXCD treatment prevented increase in MDA and decreases in activities of SOD, CAT and GSH-px in the blood of RA rat}

There was a significant increase in MDA level in RA group, relative to normal control group. The level of MDA was 4-fold higher in untreated RA rats than in normal rats. However, BXCD treatment of the RA rats for 30 days inhibited the RA-induced increase in MDA level (Figure 3). The activities of SOD, CAT and GSH-Px in the blood of RA rats were significantly lower that the corresponding activities in normal control rats. However, the expressions of these enzymes in 
RA rats were significantly increased by treatment with $10 \mathrm{mg} / \mathrm{kg} \mathrm{BXCD}$ (Figure 3).

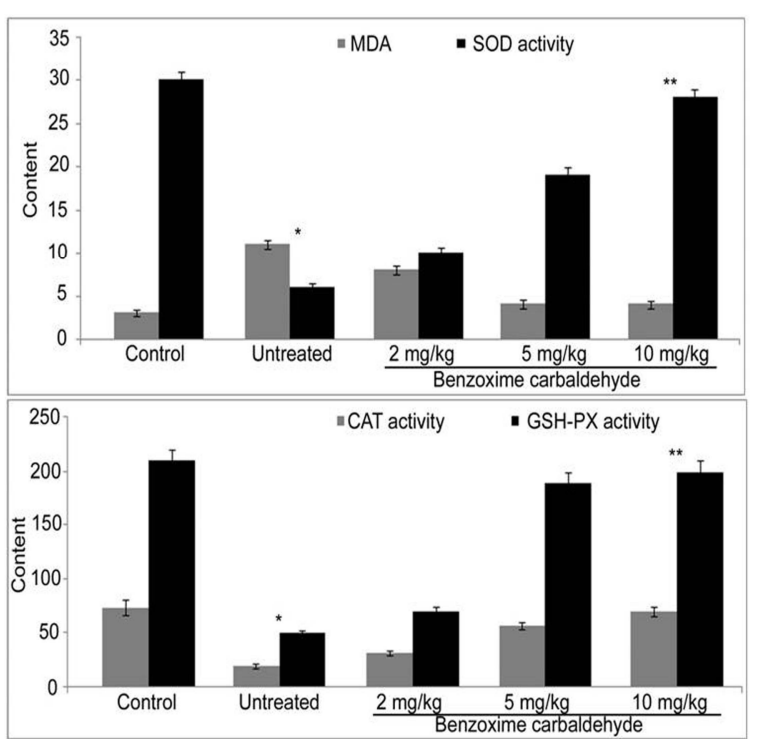

Figure 3: Effect of BXCD on levels of MDA and the expressions of SOD, CAT and GSH-Px in the blood of $\mathrm{RA}$ rats. The rat model of RA was treated for 30 days with 2,5 or $10 \mathrm{mg} / \mathrm{kg} \mathrm{BXCD.}{ }^{*} p<0.01$, compared to normal control rats, and ${ }^{* *} p<0.01$, compared to untreated rheumatoid arthritis rats

\section{BXCD down-regulated the expressions of IL- 6 , IL-1 $\beta$, NF- KB p65 unit, and TNF- $\alpha$ in RA rat blood}

The levels of IL- 6 and IL-1 $\beta$ were markedly elevated in untreated RA rats. In addition, NF-KB p65 unit and TNF- $\alpha$ in the blood of untreated RA rats were significantly higher than their corresponding levels in normal rats (Figure 4). However, treatment of RA rats with $10 \mathrm{mg} / \mathrm{kg}$ BXCD for 30 days blocked increases in the blood levels of these inflammation-related factors (Figure 4).

\section{BXCD treatment reduced COX-2 in RA rats}

Western blot assay showed that the level of COX-2 was markedly higher in RA rat tissues than in normal control rats. However, COX-2 level was significantly lowered in the RA group by BXCD treatment (Figure 5).

\section{DISCUSSION}

Rheumatoid arthritis, a chronic joint disease affecting many small and peripheral joints, is characterised by infiltration of inflammatory cells, leading to damage to cartilage and bone [13]. The present study has demonstrated the role of BXCD in the treatment of RA in a rat model, and its mechanism of action. The common symptoms of RA include joint pain, swelling, difficulties in
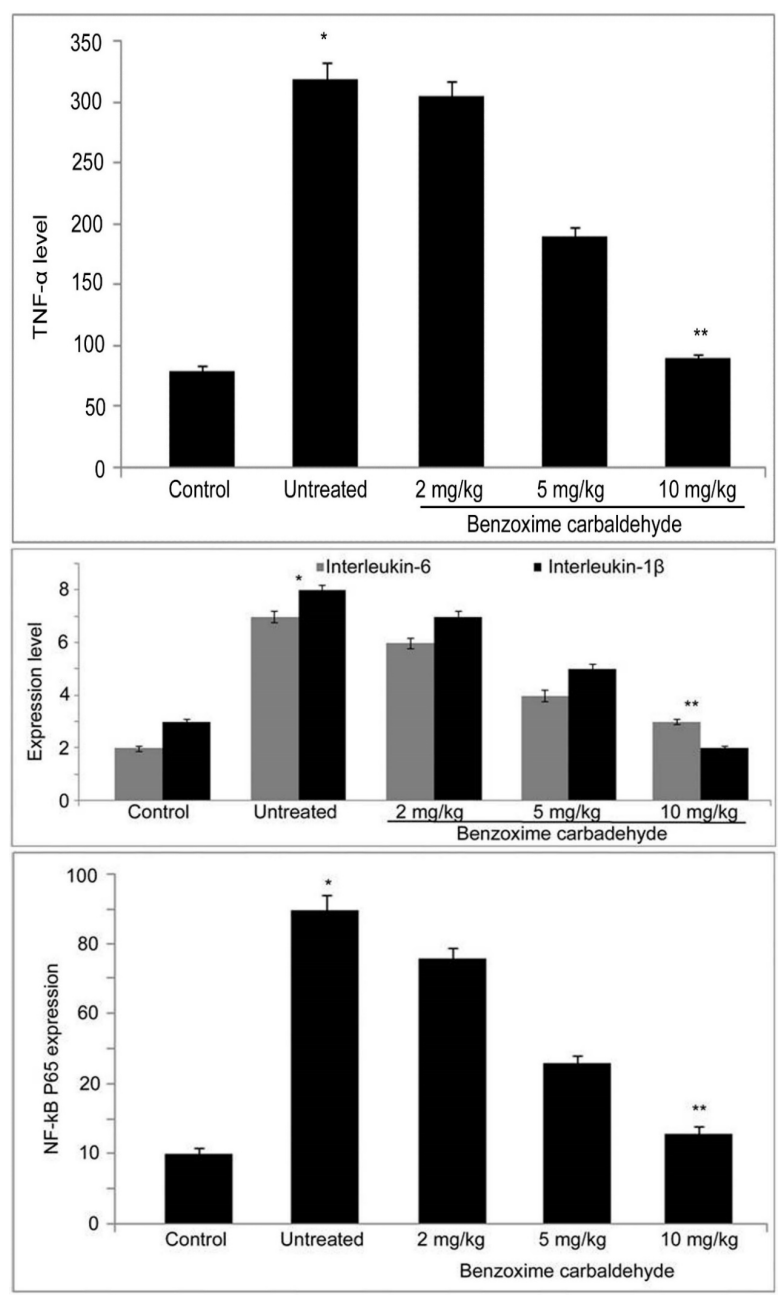

Figure 4: Effect of BXCD on IL-6, IL-1 $\beta$, NF-kB p65 and TNF- $\alpha$ levels in RA rat blood. RA rats were treated for 30 days with 2, 5 and $10 \mathrm{mg} / \mathrm{kg} \mathrm{BXCD}$ and then the levels of IL-6, IL-1 $\beta, N F-k B$ p65 unit, and TNF- $\alpha$ were determined

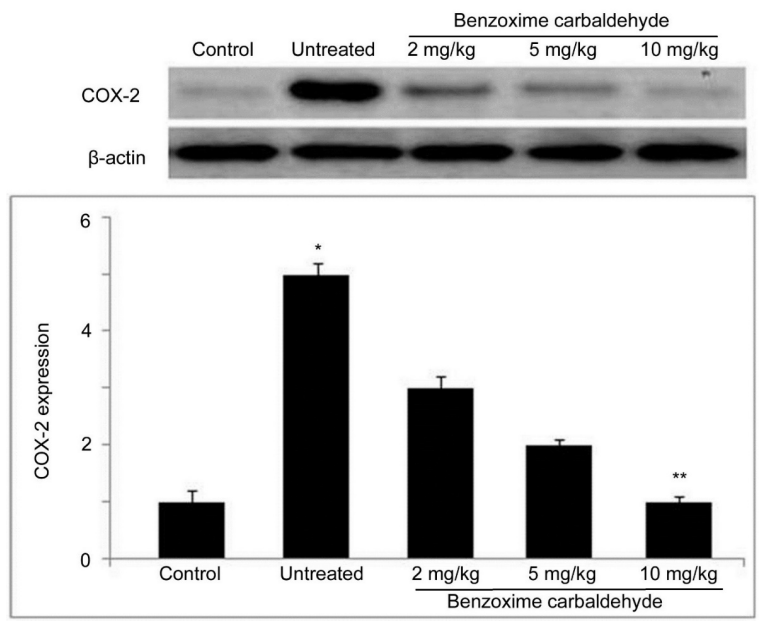

Figure 5: Effect of BXCD on COX-2 levels in RA rat tissues. The level of COX-2 in rheumatoid arthritis rats was analysed by western blot assay after 30 days treatment with BXCD 
flexibility of joints, and weight gain [14]. The present study has revealed that BXCD treatment increases the pain threshold of RA rats. This suggests that BXCD can play a role in the treatment of RA. Treatment of RA with BXCD resulted in clinical arthritis score much lower than in untreated animals. In addition, symptoms ofRA such as inflammation of joints and ear were markedly suppressed in rats after treatment with BXCD. In animal systems, accumulation of oxidants due to malfunctioning of anti-oxidant system leads to tissue damage $[15,16]$. Decrease of antioxidant enzymes in the expression of SOD have been reported to be responsible for onset of oxidative stress and development of RA [17]. The results from the current study showed that the level of MDA was higher in RA rats. However, treatment of the RA rats with $B X C D$ inhibited the increase in MDA level.

The RA-induced decreases in the activities of SOD, CAT and GSH-Px in the blood of RA rats were reversed by BXCD treatment. It has been reported that expressions of interleukin- $1 \beta$ and TNF- $\alpha$ are higher in RA patients [18]. Activation of macrophages and expression of inflammatory cytokines are thought to be associated with the degree of RA [19]. The secretion of interleukins by macrophages and chondrocytes is induced by TNF- $\alpha$ [20]. Previous studies have reported high levels of IL- 6 and IL- $1 \beta$ in RA rats. In the present study, the RA-induced increases in blood levels of NF-kB p65 unit and TNF- $\alpha$ were blocked by $\mathrm{BXCD}$ treatment.

The production of prostaglandins, inflammation and damage to tissues is catalysed by COX-2 [21]. It has been reported that the level of COX-2 in the joints of RA rats is markedly elevated [5]. Inhibition of COX-2 expression plays an important role in the suppression of arthritis [22]. The COX-2 level in the untreated RA group in the present study was significantly elevated, but was markedly lowered by BXCD treatment, suggesting a therapeutic potential of BXCD for RA.

\section{CONCLUSION}

The findings of this study demonstrate that benzoxime carbaldehyde mitigates rheumatoid arthritis by increasing pain threshold, inhibiting tissue inflammation, and blocking the expressions of inflammatory cytokines. Thus, benzoxime carbaldehyde possesses a potential for use as a therapeutic agent for the treatment of rheumatoid arthritis.

\section{DECLARATIONS}

\section{Conflict of Interest}

No conflict of interest associated with this work.

\section{Contribution of Authors}

We declare that this work was done by the authors named in this article and all liabilities pertaining to claims relating to the content of this article will be borne by the authors.

\section{REFERENCES}

1. Dhaouadi T, Sfar I, Abelmoula L, Jendoubi-Ayed $S$, Aouadi H, Ben Abdellah T, Ayed K, Zouari R, Gorgi Y. Role of immune system, apoptosis and angiogenesis in pathogenesis of rheumatoid arthritis and joint destruction, a systematic review. Tunis Med 2007; 85: 991-998.

2. Wang $K$, Zhao L, Liu X, Hao Z, Zhou Y, Yang C, Li H. Differential co-expression analysis of rheumatoid arthritis with microarray data. Mol Med Rep 2014; 10: 2421-2426.

3. Liu H, Pope RM. The role of apoptosis in rheumatoid arthritis. Curr Opin Pharmacol 2003; 3: 317-322.

4. Lu QY, Han QH, Li X, Li ZC, Pan YT, Liu L, Fu QG. Analysis of differentially expressed genes between rheumatoid arthritis and osteoarthritis based on the gene co-expression network. Mol Med Rep 2014; 10: 119-124.

5. Gheorghe KR, Sadique $S$, Leclerc $P$, Idborg H, Wobst I, Catrina Al, Jakobsson PJ, Korotkova M. Limited effect of anti-rheumatic treatment on15 prostaglandin dehydrogenase in rheumatoid arthritis synovial tissue. Arthritis Res Ther 2012; 14: R121.

6. Shahmohamadnejad $S$, Vaisi-Raygani A, Shakiba $Y$, Kiani A, Rahimi Z, Bahrehmand F, Shakiba E, Pourmotabbed T. Association between butyrylcholinesterase activity and phenotypes, paraoxonase192 rs662 gene polymorphism and their enzymatic activity with severity of rheumatoid arthritis: Correlation with systemic inflammatory markers and oxidative stress, preliminary report. Clin Biochem 2015; 48: 63-69.

7. Turhanoglu AD, Guler $H$, Yonden Z, Aslan F, Mansuroglu $A$, Ozer $C$. The relationship between vitamin $D$ and disease activity and functional health status in $R A$. Rheumatol Int 2011; 31: 911-914.

8. Prietl B, Treiber G, Pieber TR, Amrein K. Vitamin $D$ and immune function. Nutrients 2013; 5: 2502-2521.

9. Ying $H$, Yan L, Zhihua $Z$, Xiaohua $W$, Mingliang $H$, Rongjun L, Xueqing $Y$. Rosiglitazone alleviates injury in rats with adenine-induced chronic kidney disease. Mol Med Rep 2013; 8: 1831-1835.

10. Luo L, Hu L, He L, Tang ZL, Song XG, DirckinckHolmfeld $L$, Cai $R L$. Effect of moxibustion on

Trop J Pharm Res, August 2018; 17(8):1583 
ultrastructure of synovial cells in rheumatoid arthritis rats. Zhen Ci Yan Jiu 2011; 36: 105-109 (In Chinese).

11. Zheng B, Hu L, Song $X, W u Z$, Cai R, He L, Zhang $C$, Yu $Q$. Analgesic effect of different moxibustion durations in rheumatoid arthritis rats. J Tradit Chin Med 2014; 34: 90-95.

12. Zhilin J, Jiao H. Paeoniflorin ameliorates rheumatoid arthritis in rat models through oxidative stress, inflammation and cyclooxygenase 2. Expt Ther Med 2016; 11: 655-659.

13. Lee DM, Weinblatt ME. Rheumatoid arthritis. Lancet 2001; 358: 903911.

14. Almoallim HM, Alharbi LA. Rheumatoid arthritis in Saudi Arabia. Saudi Med J 2014; 35: 1442-1454.

15. Baldeiras I, Santana I, Proença MT, Garrucho MH, Pascoal $R$, Rodrigues $A$, Duro $D$, Oliveira $C R$. Peripheral oxidative damage in mild cognitive impairment and mild Alzheimer's disease. J Alzheimers Dis 2008; 15: 117-128.

16. Hitchon CA, El-Gabalawy HS. Oxidation in rheumatoid arthritis. Arthritis Res Ther 2004; 6: 265-278.

17. Toyokuni S. Molecular mechanisms of oxidative stressinduced carcinogenesis: From epidemiology to oxygenomics. IUBMB Life 2008; 60: 441-447.
18. Klein K, Kabala PA, Grabiec AM, Gay RE, Kolling C, Lin LL, Gay S, Tak PP, Prinjha RK, Ospelt C, Reedquist KA. The bromodomain protein inhibitor I-BET151 suppresses expression of inflammatory genes and matrix degrading enzymes in rheumatoid arthritis synovial fibroblasts. Ann Rheum Dis 2016; 75: 222-229.

19. Ichihara H, Yamasaki S, Hino M, Ueoka R, Matsumoto Y. Therapeutic effects of hybrid liposomes with downregulation of inflammatory cytokine for model mice of rheumatoid arthritis in vivo. Bioorg Med Chem Lett 2015; 25: 2686-2689.

20. Zhang J, Chen L, Delzell E, Muntner P, Hillegass WB, Safford MM, Millan IY, Crowson CS, Curtis JR. Republished: The association between inflammatory markers, serum lipids and the risk of cardiovascular events in patients with rheumatoid arthritis. Postgrad Med J 2014; 90: 722-729.

21. Dubois RN, Abramson SB, Crofford L, Gupta RA, Simon LS, Van De Putte LB, Lipsky PE. Cyclooxygenase in biology and disease. FASEB J 1998; 12: 1063-1073.

22. Zheng YQ, Wei W, Zhu L, Liu JX. Effects and mechanisms of Paeoniflorin, a bioactive glucoside from peony root, on adjuvant arthritis in rats. Inflamm Res 2007; 56: 182-188. 